\title{
Medication Reconciliation as a Tool to Reduce Medication Discrepancy
}

\author{
Nia Kurnia Sholihat*, Amani Hanifah, Melati Dewi Puspaningtyas, Laksmi Maharani, Esti Dyah Utami \\ Department of Pharmacy, Faculty of Health Sciences, Universitas Jenderal Soedirman, Purwokerto, Indonesia.
}

\begin{tabular}{l}
\hline ARTICLE INFO \\
\hline Article history: \\
Received on: $11 / 12 / 2017$ \\
Accepted on: $19 / 03 / 2018$ \\
Available online: $30 / 05 / 2018$
\end{tabular}

Key words:

medication reconciliation, discrepancy, pharmacist, hospital.

\begin{abstract}
Medication reconciliation is a system for identifying drug discrepancies at different point of transition to prevent medication errors and adverse drug events. This study aimed to identify discrepancies in patients receiving and not receiving medication reconciliation and to evaluate the effectiveness of the medication reconciliation process. This was an observational cohort study. Patients who transferred from the emergency room to pediatric and internal wards Dr. Margono Soekarjo Hospital $(\mathrm{n}=224)$ were arbitrarily grouped to 1$)$ patients receiving medication reconciliation, and 2) not receiving medication reconciliation. Both groups were followed to compare medication data and reconciliation process. The result showed that 185 discrepancies were found in 139 (62\%) patients who received reconciliation. Of these, $78 \%$ discrepancies were resolved by reconciliation. Meanwhile, there were found 140 discrepancies in 85 (37.9\%) patients who did not receive reconciliation. All of it could not be resolved. There was a significant difference of discrepancies $(\mathrm{p}<0.001)$ before and after reconciliation. There was also a significant difference in a number of discrepancies $(p<0.001)$ between reconciliation and non-reconciliation group. Reconciliation is beneficial to reduce discrepancies. Selection criteria of patients should be made when the health professionals performing reconciliation are limited.
\end{abstract}

\section{INTRODUCTION}

Medication discrepancy is inconsistencies between two or more medication lists; can occur at the time of hospital admission or discharge (Cornish et al., 2005; Stitt et al., 2011). Discrepancies can lead to medication errors. A study found that at least $14 \%$ patients experienced one or more medication discrepancies at hospital discharge (Coleman et al., 2005). Another study found that $23 \%$ patients also have $\geq 1$ discrepancy at hospital admission (Unroe et al., 2010).

Unintentional medication discrepancy is a risk to the patient. A study showed that $38 \%$ discrepancies had the potential to cause moderate to serious harm (Cornish et al., 2005). This was confirmed by another study that denoted $29 \%$ unintentional discrepancies also had the potential to cause possible patient discomfort and/or clinical deterioration (Wong et al., 2008).

"Corresponding Author

Nia Kurnia Sholihat, Department of Pharmacy, Faculty of Health Sciences, Universitas Jenderal Soedirman, Purwokerto, Indonesia.

E-mail:nia_sholihat@yahoo.com
Medication discrepancy can reduce with medication reconciliation at all transition points of care (Stitt et al., 2011). According to The Joint Commission, medication reconciliation is 'the process of comparing patient's medication orders to all the medications that the patient has been taking' (Sentinel Event Alert, 2006). This has been set as a part of ensuring National Patient Safety Goal in the US (The Joint Commission, 2017). In Indonesia, it is compulsory for the clinical pharmacist to perform medication reconciliation as a part of pharmaceutical care in a hospital (Ministry of Health Republic of Indonesia, 2014).

Despite many pieces of evidence proved that reconciliation can reduce discrepancy (Boockvar et al., 2006; Mueller et al., 2012; Unroe et al., 2010; Wong et al., 2008), evaluation of this system since it has been implemented in a regional secondary hospital in Indonesia has never been done. Therefore, we want to identify discrepancies in patients receiving and not receiving medication reconciliation, and to evaluate the effectiveness of the medication reconciliation process in Dr. Margono Soekarjo General Hospital, Purwokerto, Indonesia. 


\section{METHODS}

This was an observational prospective study, conducted in two periods, 25 April-25 May 2016 in the internal ward and 11 January-11 February 2017 in the pediatric ward, at Dr. Margono Soekarjo General Hospital, a secondary hospital located in Purwokerto, Indonesia. All patients who transferred from emergency to the internal or pediatric wards and have a complete medication data were included in the period of this study. Patients were excluded if they were admitted less than 24 hours. This study has been approved by the research and education section of Dr. Margono Soekarjo General Hospital. All patients included in this study has been signed the informed consent form.

Reconciliation in this hospital has been implemented since 2015. This hospital pharmacists have developed a medication reconciliation form and was assigned to perform reconciliation for every patient at a transition point of care. These clinical pharmacists continued with their normal duties during the study. The pharmacists generally obtain a medication history from the medical record or physicians' prescription in an emergency, or by interviewing patients or their families, then compare with the latest medication history in the wards. The reconciliation process was recorded in reconciliation form.

Due to the limited number of pharmacists, reconciliation could not be performed for all patients. So that, we arbitrarily grouped patients to 1) patients receiving medication reconciliation, and 2) not receiving medication reconciliation. For patients who receive medication reconciliation, we follow the pharmacist in charge in the wards to record reconciliation process, medication charts, and medical records of patients. Medication discrepancies were defined as any differences between the medication of patients in emergency and internal/pediatric wards. Medication discrepancies then were categorized based on the lists by Wong (Wong et al., 2008). Discrepancies were categorized into 3 groups: (1) drug, including omission, no indication, therapeutic duplication, inappropriate route, needs prescription to refill not addressed, inappropriate duration; (2) dose, including incorrect dose and not renally adjusted; and (3) incorrect frequency. We count the number of discrepancies, then categorized it into a type of discrepancy. For patients who did not receive reconciliation, we record medication history, both in emergency and internal/ pediatric wards, then count the number of discrepancies and type of discrepancy.

Descriptive analysis was performed to describe characteristics of patients, using Microsoft Excel. The effectiveness of reconciliation was analyzed using Wilcoxon signed rank test. The number of discrepancies in two groups was compared using Mann-Whitney U test. A p-value of less than 0.05 was considered significant. We ensured confidentiality of all data and not disclose any individual or private information of the patient. Data was presented as part of the study results as a whole.

\section{RESULTS AND DISCUSSIONS}

During the period of this study, 224 patients were included. Characteristics of patients were summarized in Table 1. Mean age in the pediatric ward was 3.9 ( $\mathrm{SD} \pm 3.9)$. It means that most patients in the pediatric ward were toddlers. In the internal ward, the mean age of the patient was $51(\mathrm{SD} \pm 13.7)$. Some of them $(17.7 \%)$ were geriatric patients.
Table 1: Characteristics of patients.

\begin{tabular}{lc}
\hline \multicolumn{1}{c}{ Characteristics of patients } & N (\%) or Mean (SD) \\
\hline Reconciliation & \\
Receive & $139(62.1)$ \\
Not receive & $85(37.9)$ \\
Age (mean, SD) & $24.1(25.2)$ \\
Pediatric ward & $4(3.9)$ \\
Internal ward & $51.1(13.7)$ \\
Gender & \\
Male & $126(56.3)$ \\
Female & $98(43.8)$ \\
\hline
\end{tabular}

Table 2: Day of reconciliation.

\begin{tabular}{cc}
\hline Day of reconciliation & $\mathbf{N}(\%)$ \\
\hline 0 & $72(51.8)$ \\
1 & $18(12.9)$ \\
2 & $16(11.5)$ \\
3 & $10(7.2)$ \\
4 & $6(4.3)$ \\
5 & $7(5.0)$ \\
6 & $3(2.2)$ \\
7 & $3(2.2)$ \\
8 & $2(1.4)$ \\
9 & $2(1.4)$ \\
Mean (SD) & $1.5(2.1)$ \\
\hline
\end{tabular}

Day of reconciliation varies greatly from day- 0 of transition to day-9 (mean day-1.5, SD 2.1) (Table 2). Ninety patients $(64.7 \%$ ) have their medication reconciled within $0-48$ hour after the transition. Many standards have suggested for reviewing the medication history should be performed within 24-hour (Barnsteiner, 2008; WHO, 2007). Another study suggested in practice setting, time of reconciliation can be expanded 24-48 hours after admission (Olavo and Kaveh, 2012). The longer the review of medication performed, the greater possibility of medication errors occurred (Quélennec et al., 2013). In this study, we found that reconciliation was done on the ninth day after the transition. This was due to lacking personnel's performing reconciliation. The responsible profession to perform reconciliation was a pharmacist, one pharmacist in each pediatric and internal ward. Though reconciliation has been done to most patients, it would result in less benefit if they were performed too long after the transition. We suggested the pharmacists pay attention at the time of doing reconciliation. Adding personnel to make reconciliation would also help to make reconciliation in time.

One hundred and eighty-five (78.1\%) discrepancies were found in $139(62.1 \%)$ patients who receive reconciliation (Table 3 ). Of these, $78 \%$ discrepancies were resolved by reconciliation. While there were found 140 discrepancies in 85 (37.9\%) patients who did not receive reconciliation. All of it could not be resolved. The effectiveness of reconciliation process was significant $(\mathrm{p}<$ 0.001 ), by comparing the number of discrepancies before and after reconciliation. This means the reconciliation process has been proved to reduce discrepancies and pharmacist plays a great 
role to prevent medication error. This result was consistent with previous studies (Boockvar et al., 2006; Mueller et al., 2012; Unroe et al., 2010) where reconciliation by pharmacists could reduce discrepancies. Pharmacist-conducted reconciliation in the emergency department also increased compliance with the hospital's medication reconciliation policy for admitted patients (Hayes et al., 2007). This study convinces hospital management to pay attention to a better system of medication reconciliation.

Table 3: Type and number of discrepancies both in patients receiving reconciliation and not receiving reconciliation.

\begin{tabular}{|c|c|c|c|}
\hline \multirow{2}{*}{$\begin{array}{c}\text { Type of } \\
\text { discrepancy }\end{array}$} & \multicolumn{2}{|c|}{ Patients received reconciliation } & \multirow{2}{*}{$\begin{array}{l}\text { Patients did } \\
\text { not receive } \\
\text { reconciliation } \\
(\mathbf{N}, \%)\end{array}$} \\
\hline & $\begin{array}{c}\mathrm{N} \text { of resolved } \\
\text { discrepancies }(\%)\end{array}$ & $\begin{array}{c}\mathrm{N} \text { of unresolved } \\
\text { discrepancies }(\%)\end{array}$ & \\
\hline \multicolumn{4}{|l|}{ Drug } \\
\hline Omission & $136(57.3)$ & $7(2.9)$ & $91(65)$ \\
\hline No indication & 0 & 0 & 0 \\
\hline Therapeutic duplication & $5(2.1)$ & 0 & $2(1.4)$ \\
\hline Inappropriate route & $7(2.9)$ & 0 & 0 \\
\hline $\begin{array}{l}\text { Needs prescription to } \\
\text { refill not addressed }\end{array}$ & 0 & 0 & 0 \\
\hline Inappropriate duration & $1(0.4)$ & $14(5.9)$ & $8(5.7)$ \\
\hline \multicolumn{4}{|l|}{ Dose } \\
\hline Incorrect & $19(8.0)$ & $27(11.4)$ & $28(20)$ \\
\hline Not renally adjusted & 0 & 0 & 0 \\
\hline \multicolumn{4}{|l|}{ Frequency } \\
\hline Incorrect & $17(7.1)$ & $4(1.7)$ & $11(7.8)$ \\
\hline Total & $185(78.1)$ & $52(21.9)$ & $140(100)$ \\
\hline
\end{tabular}

There was also a significant difference in a number of discrepancies $(p<0.001)$ between reconciliation and nonreconciliation group. This benefit of reconciliation showed in many studies. Gleason et al. proved that reconciliation by pharmacists decreased potential medication errors in admission point (Gleason et al., 2004). A systematic review of hospital-based medication reconciliation also showed that in 17 included studies, there was a reduction in medication discrepancies and a reduction in potential adverse drug events (5 of 6 studies) (Mueller et al., 2012).

Despite reconciliation process was effective $(p<$ 0.001 ), there should be evaluated in the process of performing reconciliation. Firstly, the health professional who responsible performing reconciliation in this hospital was only pharmacists. In this study, there were 2 pharmacists performing reconciliation, each in the pediatric ward and internal ward. Another health professional was found to help pharmacist to do reconciliation was a nurse. In this study, there were four nurses performing reconciliation in the pediatric ward. However, their involvement in reconciliation was voluntary. Reconciliation should be done in collaboration with other health professionals (e.g., physicians and nurses). Pronovost et al. in their study involved nurses for identifying discrepancies, resulting in reducing nearly all medication errors (Pronovost et al., 2003). Physicians played a great role in responding discrepancy $(85.9 \%)$ to review the drug regimen and add monitoring (Boockvar et al., 2006). The previous study also found that a multidisciplinary approach by nurses, pharmacists, and physicians can decrease the mean number of discrepancies during admission and discharge (Varkey et al., 2007). We suggested to the hospital management to extend the responsibility of performing reconciliation to another health professional, i.e. nurse and physician so that all patients in the transition of care could receive reconciliation.

Secondly, due to the limited number of health professionals who could perform reconciliation, there should be screening criteria for selecting patients. Patients with high-risk, including a number of prescribing physicians before admission, number of medications (four or more medication prescription), and high-alert medication or unclear history could be the priority (Etchells et al., 2009; Gleason et al., 2010). Patients prescribed more than 10 medications also tend to have medication discrepancy compared to those with fewer medications (Trompeter et al., 2014). Muller et al. defined high-risk patients as older patients (with age threshold from 55-80 years old), polypharmacy (4 to 13 medications), and have greater than 3 comorbid conditions (Mueller et al., 2012).

Thirdly, evaluation of the reconciliation form should be made. Reconciliation form that pharmacist should fill in only consisted of the name of the drug, number of drugs, the direction of use, continue the drug after admission, and continue the drug after discharge. There was no information whether the discrepancy, if any, has been confirmed to the prescribing physicians or not; or information for internal transfer; or obtaining best possible medication history (BPMH) of the patient. We suggested revising the medication reconciliation form to be more structured so that there would be no ambiguity if they have read by other health professions. Redesigning reconciliation into a computerized or information technology-based medication reconciliation would also be an option. This system has been proven to decrease unintentional medication discrepancies with the potential to patient harm (Schnipper et al., 2009).

The type and number of discrepancies were shown in Table 3. The most common discrepancy was the omission of drug $(n=234,62.1 \%)$, e.g. ranitidine, furosemide, ketorolac, and paracetamol being used in an emergency but stopped when transferred to the wards. This usually due to condition improvement of patients. Of these, 136 discrepancies have been resolved by reconciliation. At least, every patient has a chance to have discrepancies 0.86 times (SD 1.3) when transferring from emergency towards. This result was consistent with another study where omission of drug (46.4\%) was the most identified discrepancy (Cornish et al., 2005). While other study stated that the omission of the drug as the second most common discrepancy (22.9\%) (Wong et al., 2008). Identifying type of discrepancy is important to get a better understanding of physicians to prevent them (Wong et al., 2008). A study found that even the omission of medication was a common occurrence, the physician often does not have adequate information on the reasons for changes (Akram et al., 2015). If it was the case, pharmacists should be the one who is responsible to clarify the discrepancy to the prescribing doctors.

The second common type of discrepancy in this study was incorrect dose. Cornish et al. confirmed in their study that discrepant dose was also the second most common type of discrepancy (Cornish et al., 2005). The number of unresolved discrepancies in this type was quite high (27 discrepancies, 11.4\%) when compared to another type of discrepancies. Of these, 26 
unresolved discrepancies were found in the pediatric ward. In this ward, pharmacist together with nurses performed reconciliation. Pharmacists and nurses might have different perceptions about medication reconciliation. So, we then test the difference between the number of resolved discrepancies in pharmacist group and nurses group using Mann-Whitney U-test and found that there is no significant difference between them (p-value 0.343). This might be due to both pharmacists and nurses failed to identify dose discrepancies in pediatric patients. The pediatric patient would need adjustment dose based on the child's age, weight, or clinical response (O'Hara, 2016). Failure to identify this discrepancy may cause harm to patients. We suggested to pharmacists and nurses to pay more attention to the alteration of dose in a transition point.

Medication reconciliation should be done at every transition of care in which new medications are written, including hospital admission, the transition of care setting, or discharge (Sentinel Event Alert, 2006). The limitation of this study was we only observe discrepancies in transition between emergency and wards. Previous studies found that discrepancies occur more frequently on hospital discharge than admission (Pippins et al., 2008, Varkey et al., 2007). Therefore, we suggested further study to include another reconciliation setting, i.e. admission and discharge.

In this study, we only observed a number of discrepancies, while we did not make any categorization whether the discrepancy is actual or potential. We assumed that all of the discrepancies were unintentional. All patients in this study were observed their medication record until they were admitted to the pediatric or internal wards. In patients, which discrepancies could not be resolved by reconciliation, we did not track whether they experienced an actual adverse event or not. As well as in patients, which discrepancies could be resolved, we did not predict the potential medication errors or adverse drug event. Further study was suggested to follow patients to investigate the number of actual or potential adverse event.

\section{CONCLUSIONS}

Reconciliation is beneficial to reduce discrepancies. The structured reconciliation form should be revised to ensure patient safety. Selection criteria for patients should be made when the health professionals performing reconciliation are limited.

\section{REFERENCES}

Akram F, Huggan PJ, Lim V, Huang Y, Siddiqui FJ, Assam PN, Merchant RA. Medication discrepancies and associated risk factors identified among elderly patients discharged from a tertiary hospital in Singapore. Singapore Med J. 2015; 56:379.

Barnsteiner JH. 2008. Medication Reconciliation. In: Hughes RG, Editor. Patient Safety And Quality: An Evidence-Based Handbook For Nurses. Chapter 38. Rockville (MD): Agency For Healthcare Research And Quality (US).

Boockvar KS, Lacorte HC, Giambanco V, Fridman B, Siu A. Medication reconciliation for reducing drug-discrepancy adverse events. Am J Geriatr Pharmacother. 2006; 4:236-243.

Coleman EA, Smith JD, Raha D, Min SJ. Posthospital medication discrepancies: prevalence and contributing factors. Arch Intern Med. 2005; 165:1842-1847.

Cornish PL, Knowles SR, Marchesano R, Tam V, Shadowitz S, Juurlink DN, Etchells EE. Unintended medication discrepancies at the time of hospital admission. Arch Intern Med. 2005; 165:424-429.

Etchells E, Matlow A, Coffey M, Cornish P, Koonthanam T. Implementation of admission medication reconciliation at two academic health sciences centres: challenges and success factors. Healthc Q. 2009; 12:102-109.
Gleason KM, Groszek JM, Sullivan C, Rooney D, Barnard C, Noskin GA. Reconciliation of discrepancies in medication histories and admission orders of newly hospitalized patients. Am J Health Syst Pharm. 2004; 61:1689-1694.

Gleason KM, Mcdaniel MR, Feinglass J, Baker DW, Lindquist L, Liss D, Noskin GA. Results of the medications at transitions and clinical handoffs (MATCH) study: an analysis of medication reconciliation errors and risk factors at hospital admission. J Gen Intern Med. 2010; 25:441-447.

Hayes BD, Donovan JL, Smith BS, Hartman CA. Pharmacistconducted medication reconciliation in an emergency department. Am J Health Syst Pharm. 2007; 64(16):1720-3.

Ministry of Health Republic of Indonesia. 2014. Peraturan Menteri Kesehatan Republik Indonesia Nomor 58 Tahun 2014 tentang Standar Pelayanan Kefarmasian di Rumah Sakit. In: Kementerian Kesehatan, (Ed.). Jakarta.

Mueller SK, Sponsler KC, Kripalani S, Schnipper JL. Hospitalbased medication reconciliation practices: a systematic review. Arch Intern Med. 2012; 172:1057-1069.

O'Hara K. Paediatric pharmacokinetics and drug doses. Aust Prescr. 2016; 39:208-210.

Olavo F, Kaveh GS. Medication reconciliation in the hospital: what, why, where, when, who and how? Healthc Q. 2012; 15:42-49.

Pippins JR, Gandhi TK, Hamann C, Ndumele CD, Labonville SA, Diedrichsen EK, Carty MG, Karson AS, Bhan I, Coley CM. Classifying and predicting errors of inpatient medication reconciliation. J Gen Intern Med. 2008; 23:1414-1422.

Pronovost P, Weast B, Schwarz M, Wyskiel RM, Prow D, Milanovich SN, Berenholtz S, Dorman T, Lipsett P. Medication reconciliation: a practical tool to reduce the risk of medication errors. J Crit Care. 2003; 18:201-205.

Quélennec B, Beretz L, Paya D, Blicklé JF, Gourieux B, Andrès E, Michel B. Potential clinical impact of medication discrepancies at hospital admission. Eur J Intern Med. 2013; 24:530-535.

Schnipper JL, Hamann C, Ndumele CD, Liang CL, Carty MG, Karson AS, Bhan I, Coley CM, Poon E, Turchin A. Effect of an electronic medication reconciliation application and process redesign on potential adverse drug events: a cluster-randomized trial. Arch Intern Med. 2009; 169:771-780.

Sentinel Event Alert. Using medication reconciliation to prevent errors. Jt Comm J Qual Patient Saf [Serial Online]; 2006; 32:230-232.

Stitt DM, Elliott DP, Thompson SN. Medication discrepancies identified at time of hospital discharge in a geriatric population. Am J Geriatr Pharmacother. 2011; 9:234-240.

The Joint Commission. 2017. Ambulatory Health Care: 2017 National Patient Safety Goals [ONLINE]. Available at: https://www. Jointcommission.Org/Assets/1/6/NPSG_Chapter_AHC_Jan2017.Pdf [Accessed 26 April 2017].

Trompeter JM, Mcmillan AN, Rager ML, Fox JR. Medication discrepancies during transitions of care: a comparison study. J Healthc Qual. 2015; 37(6):325-32.

Unroe KT, Pfeiffenberger T, Riegelhaupt S, Jastrzembski J, Lokhnygina Y, Colón-Emeric C. Inpatient medication reconciliation at admission and discharge: a retrospective cohort study of age and other risk factors for medication discrepancies. Am J Geriatr Pharmacother. 2010; 8:115-126.

Varkey P, Cunningham J, O'meara J, Bonacci R, Desai N, Sheeler R. Multidisciplinary approach to inpatient medication reconciliation in an academic setting. Am J Health Syst Pharm. 2007; 64:850-854.

WHO. 2007. The High5s Project-Standard Operating Protocol For Medication Reconciliation.

Wong JD, Bajcar JM, Wong GG, Alibhai SM, Huh JH, Cesta A, Pond GR, Fernandes OA. Medication reconciliation at hospital discharge: evaluating discrepancies. Ann Pharmacoter. 2008; 42:1373-1379.

\section{How to cite this article:}

Sholihat NK, Hanifah A, Puspaningtyas MD, Maharani L, Utami ED. Medication Reconciliation as a Tool to Reduce Medication Discrepancy. J App Pharm Sci, 2018; 8(05): 115-118. 